\title{
Fibers Obtained from Alginate, Chitosan and Hybrid Used in the Development of Scaffolds
}

\author{
Daniela Camargo Furuya ${ }^{a}$, Silgia Aparecida da Costa ${ }^{a}$, Rodrigo Cardoso de Oliveira ${ }^{b}$, Humberto
}

Gomes Ferraz, ${ }^{c}$ Adalberto Pessoa Junior ${ }^{d}$, Sirlene Maria da Costa ${ }^{a}$ *

\author{
${ }^{a}$ School of Arts, Sciences and Humanities, Textile and Fashion Course, University of São Paulo, Arlindo \\ Béttio, 1000, 03828-000, Jardim Keralux, SP, Brazil \\ ${ }^{b}$ Department of Biological Sciences, Bauru School of Dentistry, University of São Paulo, Alameda Dr. \\ Octávio Pinheiro Brisolla, 9-75, Vila Universitária, 1701290, Bauru, SP, Brazil \\ ${ }^{c}$ Department of Pharmacy, School of Pharmaceutical Sciences, University of São Paulo, Av. Prof. \\ Lineu Prestes, 580, Cidade Universitária, 05508-000, Butantã, SP, Brazil \\ ${ }^{d}$ Department of Biochemical and Pharmaceutical Technology, School of Pharmaceutical Sciences, \\ University of São Paulo, Av. Prof. Lineu Prestes, 580, Cidade Universitária, 05508-000, Butantã, SP, \\ Brazil
}

Received: July 07, 2016; Revised: October 21, 2016; Accepted: December 27, 2016

\begin{abstract}
The main aim of this study was to develop scaffolds based on alginate, chitosan and hybrid fibers with and without glycerol. The scaffolds developed underwent assessments for tensile property, swelling ratio and weight loss, cellular viability, degradation and biomineralization, as well as DSC/TGA thermal analysis. Tenacity values showed that use of glycerol and the interaction between alginate and chitosan as a hybrid fiber were associated with increasing tenacity values. In the swelling and weight loss study, the scaffolds containing glycerol presented lower weight loss and higher water absorption values in all scaffolds, compared to scaffolds without glycerol, indicating that glycerol acted as a stabilizer. None of the alginate, chitosan and hybrid scaffolds, with or without glycerol, decreased cell viability. On the third day of the biomineralization assay, chitosan without glycerol indicated the presence of apatite crystals. The degradation study showed that glycerol may have acted as a stabilizer.
\end{abstract}

Keywords: Alginate, chitosan, fiber, scaffolds, tissue engineering

\section{Introduction}

Bone tissue engineering is a multidisciplinary field, focused on designing a scaffold to mimic the environment of the extracellular matrix and the study of more efficient signaling molecules and growth factors that stimulate regeneration. Thus, the scaffold has to behave as a temporary structure supporting bone tissue regeneration while it degrades and is replaced with the new bone ${ }^{1,2}$.

Textiles have been used in a wide range of medical devices, i.e., in contact with biological environments, such as vascular grafts, repair meshes, etc. ${ }^{3}$ Fibers are particularly useful for producing scaffolds due to their inherent properties, such as satisfactory porosity, adjustable elastic modulus and light weight, which promote tissue regeneration ${ }^{4}$. There are several different methods of producing fiber-based scaffolds, such as electrospinning, meltspinning, wetspinning, biospinning and microfluidic spinning ${ }^{5,6}$. The wetspinning method was chosen for this study.

The ideal scaffold will have a number of properties, such as biocompatibility, biodegradability, desirable pore size and satisfactory porosity, non-toxic responses, easy handling and an abundant source of raw material ${ }^{7,8}$. Scaffold porosity does not need to be uniform, because natural bone is not uniform ${ }^{8}$, which is another reason for using fibers to develop these scaffolds.

The biopolymers selected for this study were alginate and chitosan. Alginate is a polysaccharide derived from brown algae and it comprises $1 / 4$ linked $\beta$-D-mannuronic acid (M) and its $\alpha$-L-guluronic acid (G). The properties of alginate are related to the proportion and dimension of the guluronic blocks $(\mathrm{G})$ in the chain'. It is biocompatible, biodegradable, and has the ability to absorb 200-300 times its own weight, thus showing potential for use as a Drug Delivery System ${ }^{10}$. Alginate scaffolds have the ability to support tissue regeneration, including bone, skin, liver, etc $^{7}$. Chitosan is a natural polymer derived from the partial deacetylation of chitin, obtained from the exoskeleton of crustaceans. It is the most abundant cationic polysaccharide and the second most abundant in nature, behind only cellulose. It comprises (1-4)-2-acetamido-2-deoxy- $\beta$-D-glucan (N-acetyl D-glucosamine) and (1-4)-2-amino-2-deoxy-BD-glucan (D-glucosamine) units. It is also a biocompatible and biodegradable polymer and it is osteoconductive, as well as hemostatic and antimicrobial ${ }^{11}$. Chitosan scaffolds are biodegradable and tissue biocompatible. However, this polymer is mechanically weak, which is why it needs to be used in conjunction with another polymer ${ }^{12}$. 
The interaction between alginate and chitosan generates a polyelectrolyte complex that can be obtained by precipitating cationic polymers when mixed with anionic polymers in aqueous solutions, leading to mutual precipitation, which occurs in this case, because alginate and chitosan are anionic and cationic polysaccharides, respectively ${ }^{13}$. Another advantage of the interaction between its opposite charges is an upgrade in the mechanical strength of the developed structure formed by these two polymers ${ }^{14,15}$. This combination is significant for scaffold development, because while alginate offers functional groups for cellular regeneration, chitosan supports the scaffold structure ${ }^{16}$. Finally, the interaction of these two polymers creates a strong connection between them, because alginate is a hydrophilic polysaccharide and promotes low protein adsorption, different from chitosan, a less hydrophilic polysaccharide that promotes high protein adsorption ${ }^{17,18}$.

The aim of this study is to develop and characterize scaffolds based on alginate, chitosan and hybrid alginate/ chitosan fibers. All scaffolds were produced with and without glycerol in order to identify any positive properties as potential plasticizers.

\section{Materials and Methods}

\subsection{Materials}

Sodium alginate $(20,000-40,000$ cps viscosity), crabextracted chitosan ( $85 \%$ deacetylation minimum) and all reagents used were acquired from Sigma Co. (St. Louis, ME, USA).

\subsection{Methods}

\subsubsection{Preparation of alginate, chitosan and hybrid fibers with and without glycerol}

Alginate, chitosan and hybrid fibers were produced using the wet spinning technique with a syringe (Hypodermic syringes, polypropylene Luer-lock tip, capacity $10 \mathrm{~mL}$, graduated, $25 \times 7 \mathrm{~mm}$ and needle $\varnothing 0.6 \times \mathrm{L} 2.5 \mathrm{~mm}$ ).

Alginate $5 \%(\mathrm{~m} / \mathrm{v})$ was dissolved in $100 \mathrm{~mL}$ of $0.1 \mathrm{M}$ sodium hydroxide by stirring at room temperature overnight. The sodium alginate solution with and without glycerol was injected into a coagulation bath at $30^{\circ} \mathrm{C}$ containing $2 \%$ calcium chloride $(\mathrm{m} / \mathrm{v})$. Chitosan $2.2 \%(\mathrm{~m} / \mathrm{v})$ was dissolved in 200 $\mathrm{mL}$ of $2 \%$ acetic acid $(\mathrm{v} / \mathrm{v})$ by stirring at room temperature overnight and subsequently adding $250 \mathrm{~mL}$ of methanol (v/v). The chitosan gel was filtered using a vacuum pump. The chitosan gel with and without glycerol was injected into a coagulation bath at $30^{\circ} \mathrm{C}$ containing $300 \mathrm{~mL}$ of 0.5 $\mathrm{M}$ sodium sulfate, $100 \mathrm{~mL}$ of $1 \mathrm{M}$ sodium hydroxide and $600 \mathrm{~mL}$ of distilled water. The resultant fibers were extracted from this coagulation medium after 24 hours and placed in $50 \%$ methanol for $2 \mathrm{~h}$. Hybrid fibers were produced by extruding the alginate gel, with and without glycerol, in a solution containing $50 \%$ calcium chloride solution (v/v) and $50 \%$ of $0.02 \%$ chitosan gel $(\mathrm{m} / \mathrm{v})$. The fibers remained in this solution for $24 \mathrm{~h}$. Subsequently, the fibers were stored in $50 \%(\mathrm{v} / \mathrm{v})$ methanol for 2 h. $2.5 \%$ glycerol $(\mathrm{m} / \mathrm{m})$ was added to all gel solutions in order to ascertain its effect as a plasticizer. The resultant alginate, chitosan and hybrid fibers were washed three times in distilled water and part of the fibers were rolled manually on a polypropylene cylindrical support, dried at room temperature conditions for $24 \mathrm{~h}$ and characterized according to item 2.2.3. The other part of the fibers were used to produce the scaffolds (item 2.2.2).

\subsubsection{Preparation of alginate, chitosan and hybrid scaffolds with and without glycerol}

The alginate, chitosan and hybrid scaffolds were developed using the freeze-drying method. After production (item 2.2.1), the fibers previously weighed in a mass of approximately $0.255 \mathrm{~g}$, were placed in a polystyrene mold and stored in a ultrafreezer at $-67^{\circ} \mathrm{C}$ for $2 \mathrm{~h}$ to freeze the structures. Then these structures were lyophilized in a L101 Liotop lyophilizer until dried, a process lasting approximately $60 \mathrm{~h}$ at $-30{ }^{\circ} \mathrm{C}$.

The scaffolds were produced using two different polystyrene molds, both with external dimensions of 8.54 $\mathrm{x} 12.76 \mathrm{~cm}$. The mold for the production of large structures corresponded to the 12-well cell culture plate, with a diameter and depth of approximately $15 \mathrm{~mm}$ per well. The mold for the production of small structures corresponded to the 96well plate for cell cultures, with $6.4 \mathrm{~mm}$ deep wells. The production process for the scaffolds was the same for both molds. The smaller structures were prepared to facilitate the coverage of the samples in microscopy assays. The scaffolds produced in the large mold were characterized for cell viability (item 2.2.4.3), DSC / TGA (item 2.2.4.1) and absorption and weight loss (item 2.2.4.2). While the scaffolds produced in the small mold were characterized for biomineralization (item 2.2.4.5), degradation with lysozyme (item 2.2.4.4) and SEM/EDS.

\subsubsection{Mechanical testing of the fibers}

For diameter and linear density determinations in accordance with ISO $5084(1996)^{19}$, dried samples fibers were stored at $20 \pm 2{ }^{\circ} \mathrm{C}$ and relative humidity of $65 \pm 4 \%$ for $24 \mathrm{~h}$. After acclimatization, each sample was weighed using an analytical balance (AUW220D, Shimadzu, São Paulo, Brazil). The results obtained represent the ratio between the weight and the fiber length ${ }^{20}$. The assay was performed based on ISO $2060(1994)^{21}$, ISO $1139(1973)^{22}$ and ISO 139 $(2005)^{23}$. Tensile properties of the acclimatized fibers (rupture strength, tenacity, elongation and Young's modulus) were determined according to ASTM D 3822 (2007) ${ }^{24}$ using an Instron tester machine (model 5569, Norwood-MA, USA). 
Accordingly, in order to determine tenacity (strength value shared by linear density), fiber fineness (linear density or count number) was calculated in terms of TEX, defined as the weight in grams per $1,000 \mathrm{~m}$ of fiber, by weighing a known length of the fiber. A load cell of $10 \mathrm{~N}$, gauge length of 200 $\mathrm{mm}$, automatic pre-tension and crosshead speed of $100 \mathrm{~mm} /$ min were used. The tensile parameters were determined when the fiber broke immediately after maximum elongation.

\subsubsection{Characterization of the scaffolds}

\subsubsection{Differential Scanning Calorimetry - DSC/ Thermogravimetry - TGA}

DSC tests were performed in the DSC 7020 (Exstar, SII Nano Technology In., Japan) under an inert nitrogen atmosphere at a flow rate of $50 \mathrm{~mL} / \mathrm{min}$. Temperatures ranged from $25-350{ }^{\circ} \mathrm{C}$ with a heating rate of $10^{\circ} \mathrm{C} / \mathrm{min}$. A closed aluminum capsule containing $2 \mathrm{mg}$ of sample mass was used. The temperature and fusion heat were calibrated with Indium.

TG analysis was performed in a TG/DTA 7200 (Exstar, SII Nano Technology In., Japan) under a $100 \mathrm{~mL} / \mathrm{min}$ nitrogen atmosphere. Temperatures ranged from $25-600{ }^{\circ} \mathrm{C}$ with heating rate of $10^{\circ} \mathrm{C} / \mathrm{min}$. Closed platinum capsules containing $3.5 \mathrm{mg}$ of sample mass were used. The temperature and heat fusion were calibrated with Calcium oxalate before the assay.

Both DSC and TG analyses were performed with alginate and chitosan polymers and of alginate, chitosan and hybrid fiber scaffolds, with and without glycerol.

The assay was performed at the Department of Pharmacy, School of Pharmaceutical Sciences.

\subsubsection{Studies on water uptake or swelling and weight loss}

Swelling behavior and scaffold weight loss were performed in triplicate. The scaffolds were weighed and immersed in 10 $\mathrm{mL}$ of distilled water. The flask samples $(15 \mathrm{~mL})$ were closed with Parafilm (Pechiney Plastic Packaging Co., Chicago, IL, USA) and placed in a thermo regulated bath (TEC-420, Tecnal, Piracicaba, Brazil) under agitation $(60 \mathrm{rpm})$, at $37^{\circ} \mathrm{C}$ for 1, 3, 7, 15, 21 and 30 days. For water uptake calculation, an analytical balance (AUW220D, Shimadzu, São Paulo, Brazil) was used to determine the initial scaffold mass (mi) and the final mass ( $\mathrm{mw}$ ), after incubation and removal of the excess solution with filter paper. Subsequently, the scaffolds were dried at $40^{\circ} \mathrm{C}$ until constant weight was attained in order to determine (mf). Water uptake and weight loss are calculated by equations 1 and 2 .

$$
\begin{aligned}
& \text { Water uptake }=\left[\left(m_{W}-m_{i}\right) / m_{i}\right] \times 100 \\
& \text { Weight loss }=\left[\left(m_{f}-m_{i}\right) / m_{i}\right] \times 100
\end{aligned}
$$

\subsubsection{Cell viability assay}

\subsection{Cell culture}

For this study, NIH3T3 P12 fibroblasts (ATCC - American Type Culture Collection) were used. Cells were cultivated in Dulbecco's modified Eagle medium (DMEM) supplemented with $10 \%$ bovine fetal serum (FBS - NUTRICELL) and incubated in an incubator at $37{ }^{\circ} \mathrm{C}$ containing $5 \% \mathrm{CO}_{2}$. After subconfluence, cells were subcultivated with trypsin $\left(0.25 \%\right.$ trypsin, $1 \mathrm{mM}$ EDTA - Sigma Aldrich $\left.{ }^{\circledR}\right)$, in order to dissociate cells from the culture flasks, and maintained for 5 min in the incubator at $37^{\circ} \mathrm{C}$ with $5 \% \mathrm{CO}_{2}$. Then the trypsin was inactivated from DMEM using $10 \%$ FBS. Cells were transferred to $15 \mathrm{~mL}$ Falcon tubes $\left(\mathrm{TPP}^{\circledR}\right.$ - Techno Plastic Products) and centrifuged for $5 \mathrm{~min}$ at $4{ }^{\circ} \mathrm{C}$ and $1200 \mathrm{rpm}$. Subsequently, the supernatant was discarded and cells were resuspended in new DMEM with $10 \%$ FBS. Cellular account was made with trypan blue protocol and cells were used for experimental assays of MTT and crystal violet.

According to ISO No. 10.993-5, the concentrations used in this study were $10 \mathrm{mg}$ extract (samples of alginate, chitosan and hybrid scaffolds, with and without glycerol) for $1 \mathrm{~mL}$ DMEM with $10 \% \mathrm{FBS}$, i.e., proportion of 10 $\mathrm{mg} / 1 \mathrm{~mL}$. For viability assays, $2 \times 10^{3}$ cells/well were plated in 96 wells plates. After the 24-hour incubation period, the medium was replaced with DMEM with $10 \%$ FBS and conditioned with the scaffolds. Control groups received only the DMEM medium: with $10 \%$ FBS (positive control) and $1 \%$ FBS (negative control). Each plate was analyzed in an experimental period of 24 and $48 \mathrm{~h}$ after the addition of the conditioned medium ${ }^{25}$.

\subsection{MTT}

After each experimental period ( 24 and $48 \mathrm{~h}$ ), cells were washed with PBS and incubated in a solution containing 0.5 $\mathrm{mg}$ MTT for $1 \mathrm{~mL} \mathrm{DMEM}$ without FBS. After this procedure, the plates were maintained at $37^{\circ} \mathrm{C}$ for $4 \mathrm{~h}$, when the solution was removed and the insoluble pigment was extracted in dimethyl sulfoxide (DMSO). Absorbance was measured at $562 \mathrm{~nm}$ by Synergy H1 Monochromator based Biotek.

\subsection{Crystal Violet}

After each experimental period ( 24 and $48 \mathrm{~h}$ ), cells were washed with PBS and 100\% methanol was added for $10 \mathrm{~min}$. After the methanol was removed, $0.2 \%$ crystal violet solution was added to $20 \%$ ethanol for $3 \mathrm{~min}$. Then the solution was removed and the wells were washed twice with PBS to remove the excess dye. Finally, 0.05 mol.L $\mathrm{L}^{-1}$ of sodium citrate solution was added with $50 \%$ ethanol for $10 \mathrm{~min}$. Absorbance was determined at $540 \mathrm{~nm}$ by Synergy H1 Monochromator based Biotek. 


\subsection{Statistical Analysis}

MTT and Crystal violet statistical analyses were performed using GraphPad Prism 4 software selecting statistical test one way ANOVA using Tukey's test with $p<0.05$ indicating statistical significance. The cellular viability assay was performed in the Biochemistry Laboratory at the Biological Sciences Department of the Bauru School of Dentistry, University of São Paulo.

\subsubsection{In vitro degradation study}

This study was performed in triplicate in order to determine the influence of the lysozyme on the scaffold properties. The chitosan and hybrid scaffolds, with and without glycerol, weighing approximately $0.100 \mathrm{~g}$ were immersed in $10 \mathrm{~mL}$ of PBS pH $7.4 \pm 0.02$ containing lysozyme (EC 3.1.2.17, chicken egg white, $40000 \mathrm{U} / \mathrm{mg}$, Sigma), similar to that found in human serum $(13 \mathrm{mg} / \mathrm{L})$, and incubated at $37^{\circ} \mathrm{C}$ at different time intervals $(1,3,5,7$ and 10 days) under static conditions. After each incubation time, the scaffolds were dried at $40{ }^{\circ} \mathrm{C}$ and subjected to SEM analysis. After these incubation periods, the concentration of reducing sugars were determined by DNS method ${ }^{26}$. Absorption and weight loss were determined as outlined above (item 2.2.4.2).

\subsubsection{In vitro biomineralization study}

The biomineralization assay was performed in triplicate. The alginate, chitosan and hybrid scaffolds, with and without, glycerol weighing approximately $0.100 \mathrm{~g}$ were immersed in $10 \mathrm{~mL}$ of $1 \mathrm{x}$ simulated body fluid (SBF) and then incubated at $37^{\circ} \mathrm{C}$ in closed Falcon tubes for preset time periods of 1 , $3,5,7,15,21$ and 30 days. SBF is a solution that contains the necessary minerals to mimic the body fluid, prepared according to the method ${ }^{27}$. After the preset time interval, the scaffolds were removed and dried in $40{ }^{\circ} \mathrm{C}$. The dried scaffolds were subjected to SEM analysis for examination of mineralization.

\section{Results and Discussion}

\subsection{Mechanical testing}

Tension testing or material behavior under strength and deformations applied along the axis is one of the most important characteristics related to mechanical properties ${ }^{28}$. Fiber tenacity is the quotient of breaking load by the count number. This calculation is necessary in order to normalize the effect of different thickness values found in some samples containing several fibers ${ }^{20}$. Table 1 shows the tenacity values of all fibers. Tenacity values for alginate, chitosan and hybrid fibers were between 7.25-7.77, 4.47-8.64 and $9.97-10.0 \mathrm{cN} /$ tex, and the use of glycerol is associated with a trend of increasing tenacity values. The tenacity values obtained in this study are slightly inferior to those found in literature $(14.0-18 \mathrm{cN} / \mathrm{Tex})^{29}$ and $(11.0-18 \mathrm{cN} / \mathrm{Tex})^{30,31}$. However, it is worth mentioning that the cited references do not mention the alginate concentrations used. Hybrid fibers presented an increase of $27.3 \%$ and $55.2 \%$ in tenacity values compared to alginate and chitosan, respectively.

\subsection{Scaffold preparation}

The results of scaffold production can be observed in Figures 1 and 2. The scaffolds presented an interconnected porous structure due to fiber structure.

\section{3. $D S C / T G A$}

Differential Scanning Calorimetry is an important study of a material thermal behavior that identifies mass loss, reduction reactions and desorption by the endothermic peaks and crystallization, polymerization reactions and oxidation by the exothermic peaks ${ }^{32}$. The results of the DSC of the scaffolds with and without glycerol are analyzed in Figure 3.

According to the thermogram of the scaffolds without glycerol (Figure 3a), endothermic peaks of alginate occurred at $122.4{ }^{\circ} \mathrm{C}$ and $195.6{ }^{\circ} \mathrm{C}$, of chitosan at $181{ }^{\circ} \mathrm{C}$ and the hybrid at $174.2{ }^{\circ} \mathrm{C}$. Comparing these peaks, the hybrid endothermic peak is located in a intermediate temperature between alginate and chitosan. The exothermic peaks of alginate occurred at $271.7^{\circ} \mathrm{C}$, of chitosan at $304.1{ }^{\circ} \mathrm{C}$ and the hybrid at $277.7^{\circ} \mathrm{C}$. A displacement of the hybrid peaks (both, endothermic and exothermic) was noted, with regard to the polymers themselves, indicating the formation of new chemical bonds and the interaction of alginate and chitosan.

In the thermogram of scaffolds with glycerol (Figure 3b), a displacement of the hybrid endothermic and exothermic peaks occurred, with regard to the alginate and chitosan peaks, which indicates the same behavior noted in the thermogram of the scaffolds without glycerol (Figure 3a). The hybrid endothermic peak occurred at $173.9^{\circ} \mathrm{C}$ and the exothermic peak at $277.5^{\circ} \mathrm{C}$. In all scaffolds with glycerol, a displacement of the endothermic and exothermic peaks was noted, compared to the results of scaffolds without glycerol, indicating the interaction between the polymers and the glycerol.

Through thermogravimetry, the relationship between material mass and its temperature could be detected. The decomposition of the polymers can be analyzed, indicating weight loss of the sample or water evaporation ${ }^{33}$. The TGA results are analyzed in Figure 4.

The thermogram showed similar behavior of the alginate and hybrid scaffolds without glycerol, presenting three mass losses, pertaining to water evaporation and polymer degradation. The chitosan scaffold without glycerol presented two mass losses associated with the dehydration process of saccharide rings, decomposition of acetylated 
Table 1. Tenacity values of alginate, chitosan and hybrid fibers without and with glycerol

\begin{tabular}{lccccc}
\hline Fibers & Linear density (tex) & Breaking Load (N) & Tenacity (cN/tex) & Elongation (\%) & $\begin{array}{c}\text { Young's Modulus } \\
\text { (N/tex) }\end{array}$ \\
\hline Alginate & $22.3 \pm 0.98$ & $1.63 \pm 0.11$ & $7.25 \pm 0.51$ & $4.89 \pm 2.43$ & $4.77 \pm 0.49$ \\
Alginate with glycerol & $17.1 \pm 0.63$ & $1.35 \pm 0.25$ & $7.77 \pm 1.39$ & $5.41 \pm 0.45$ & $5.02 \pm 0.45$ \\
Chitosan & $17.2 \pm 0.7$ & $0.77 \pm 0.05$ & $4.47 \pm 0.28$ & $1.45 \pm 0.97$ & $4.16 \pm 1.01$ \\
Chitosan with glycerol & $17.2 \pm 0.65$ & $1.49 \pm 0.08$ & $8.64 \pm 0.51$ & $4.25 \pm 2.83$ & $5.55 \pm 0.41$ \\
Hybrid & $23.4 \pm 1.8$ & $2.23 \pm 0.24$ & $9.97 \pm 0.99$ & $6.86 \pm 1.32$ & $5.64 \pm 0.94$ \\
Hybrid with glycerol & $20.9 \pm 2.01$ & $2.09 \pm 0.12$ & $10 \pm 0.80$ & $6.58 \pm 1.91$ & $5.73 \pm 0.64$ \\
\hline
\end{tabular}

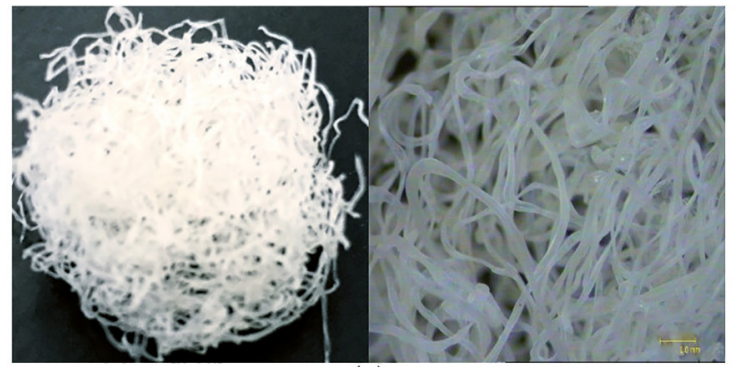

(a)

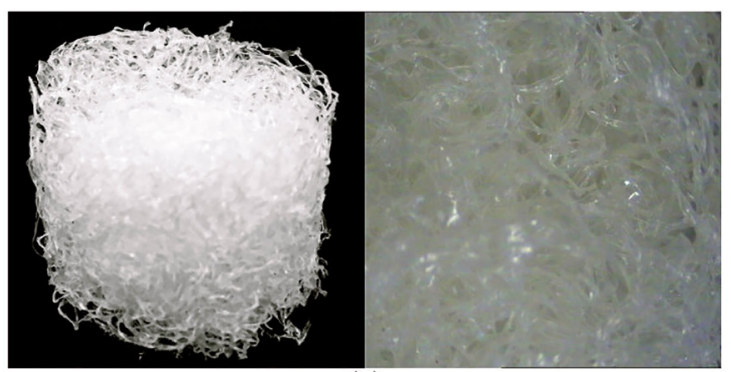

(c)

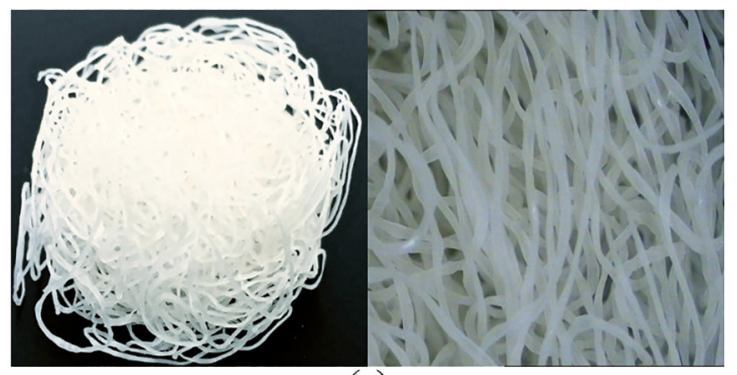

(e)

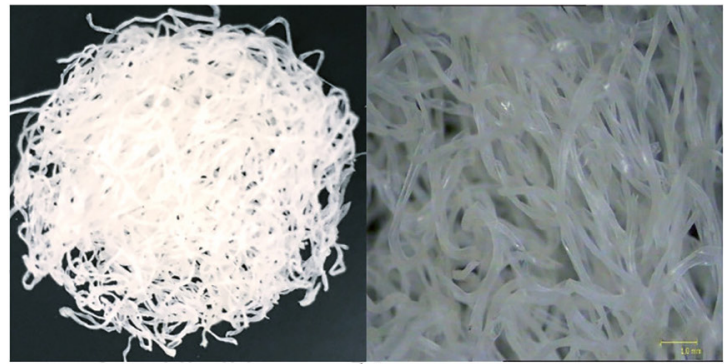

(b)

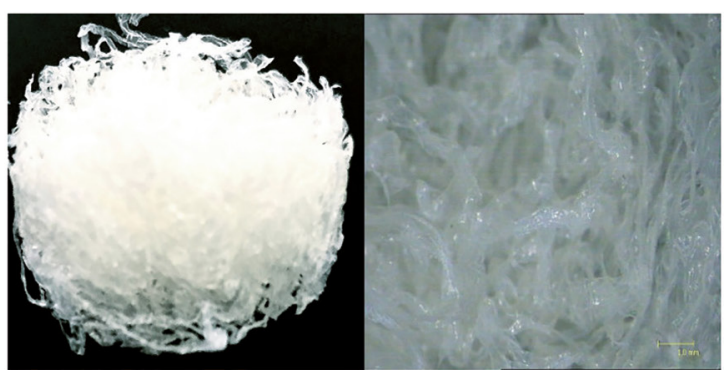

(d)

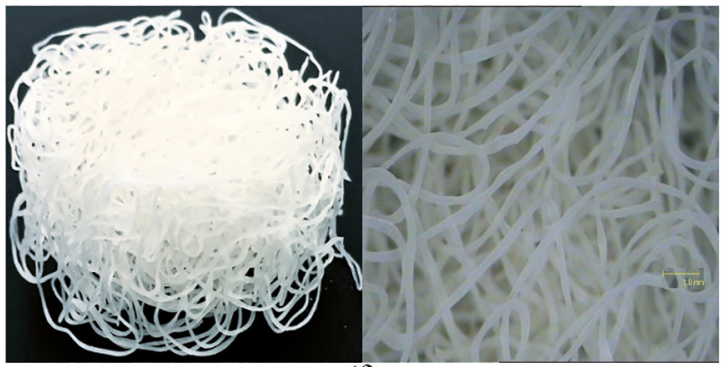

(f)

Figure 1: Scaffolds of (a) alginate without glycerol, (b) alginate with glycerol, (c) chitosan without glycerol, (d) chitosan with glycerol, (e) hybrid without glycerol and (f) hybrid with glycerol produced in mold of $15 \mathrm{~mm}$ per well in digital image and optical microscopy with 20x magnification.

and deacetylated units of chitosan and depolymerization ${ }^{34}$. The scaffolds with glycerol behaved in a similar fashion to the scaffolds without glycerol.

\subsection{Swelling studies and weight loss}

In tissue engineering, swelling ability is responsible for the polymeric matrix expansion related to scaffold morphology and cell-nutrient transmission ${ }^{15,35}$. The swelling ratio and the weight loss of the scaffolds produced are analyzed in Figure 5.

The swelling behavior results of the scaffolds without glycerol showed a gradual increase in the water uptake within thirty days. The swelling ratio of the scaffolds with glycerol showed that chitosan scaffolds presented the highest ratio of water uptake, at $1027.6 \%$ compared to $605.7 \%$ from alginate and $569.3 \%$ for hybrid scaffolds. The scaffolds 


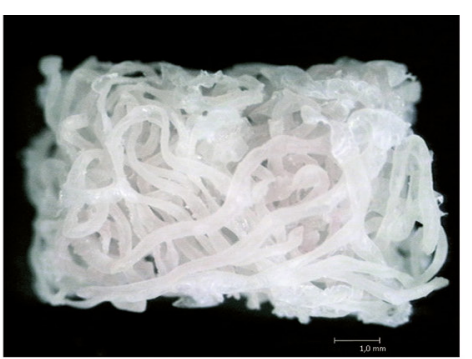

(a)

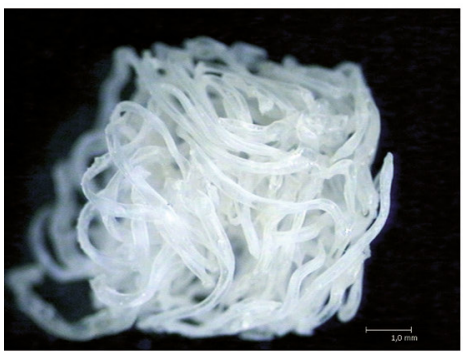

(d)

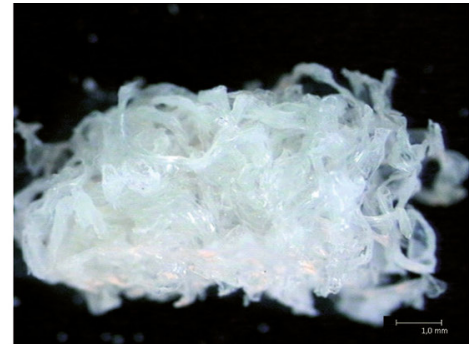

(b)

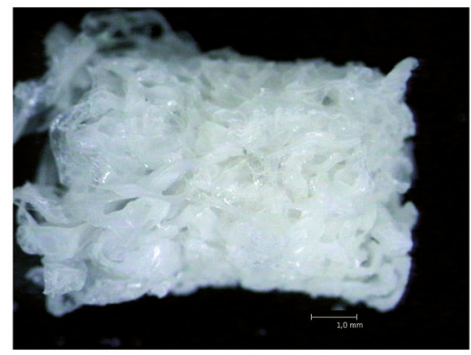

(e)

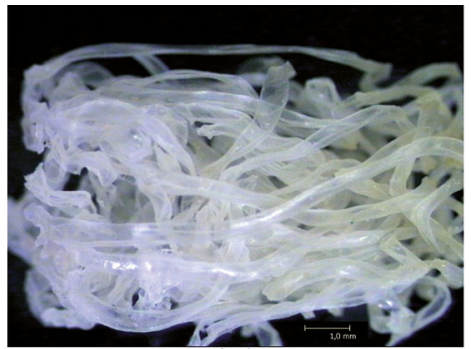

(c)

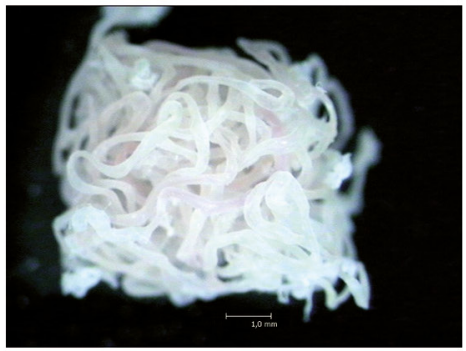

(f)

Figure 2. Optical microscopy of (a) alginate without glycerol, (b) chitosan withoutglycerol, (c) hybrid without glycerol, (d), alginate with glycerol, (e) chitosan with glycerol and (f) hybrid with glycerol scaffolds produced in mold of $6.4 \mathrm{~mm}$ per well with $20 \mathrm{x}$ magnification.

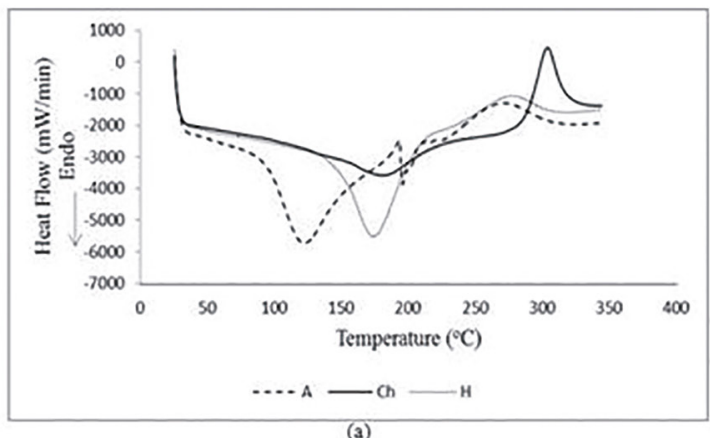

Figure 3: DSC peaks of scaffolds based on alginate, chitosan and hybrid (a) without and (b) with glycerol.

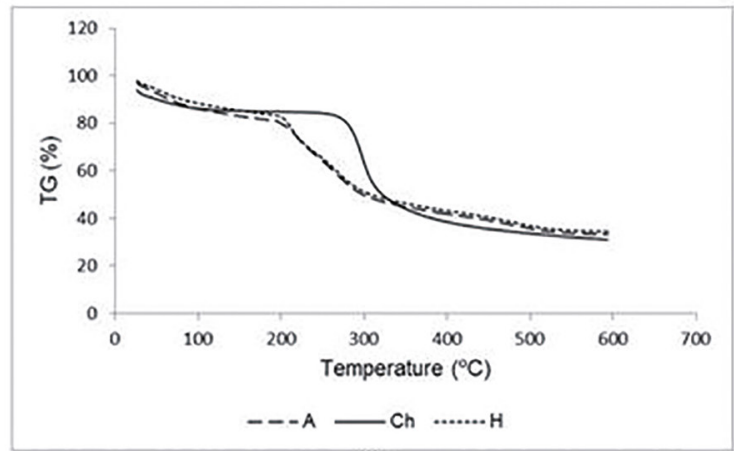

(a)

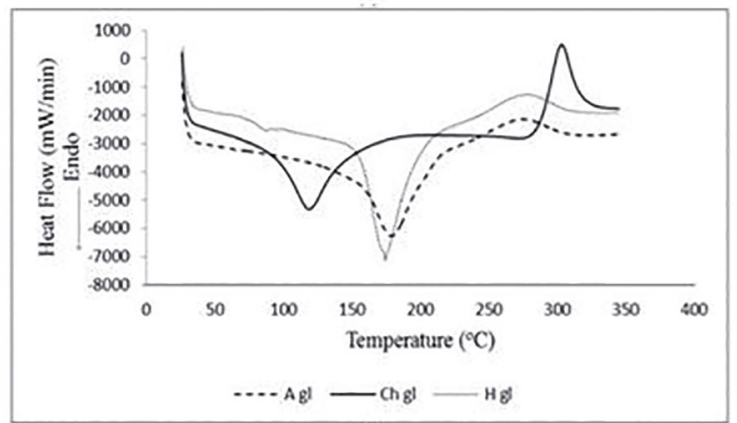

(b)

Figure 4: TGA the alginate, chitosan and hybrid scaffolds (a) without and (b) with glycerol. 


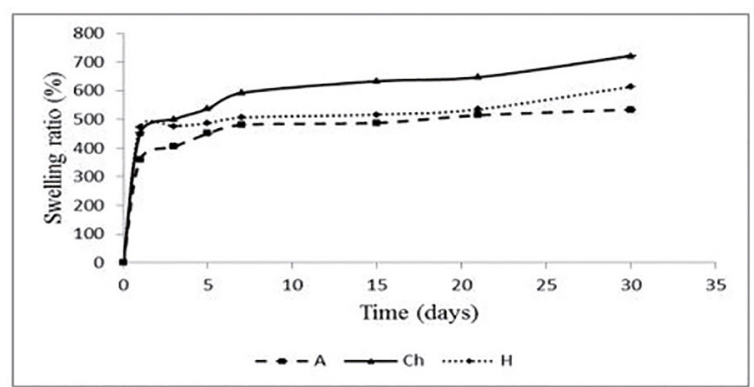

(a)

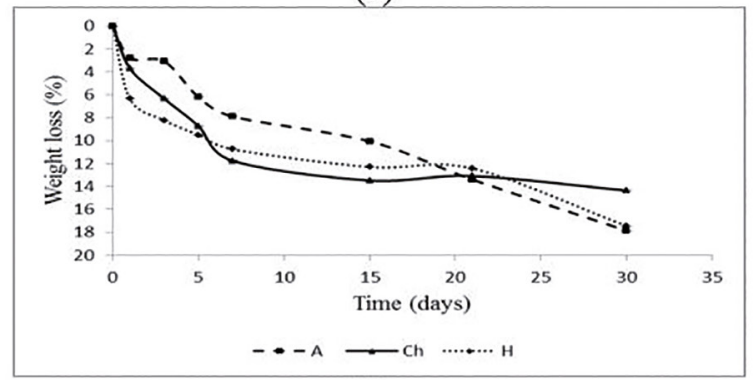

(c)

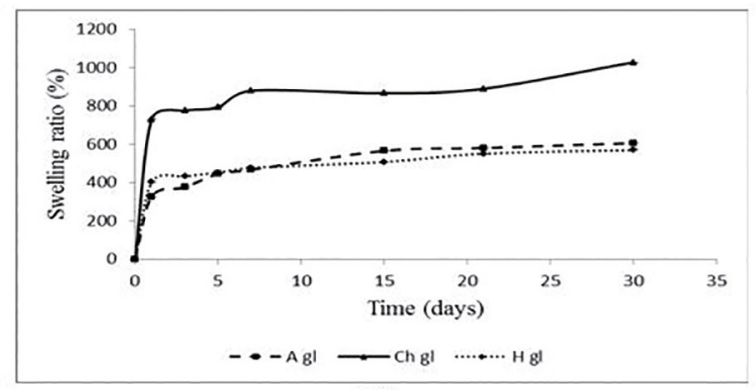

(b)

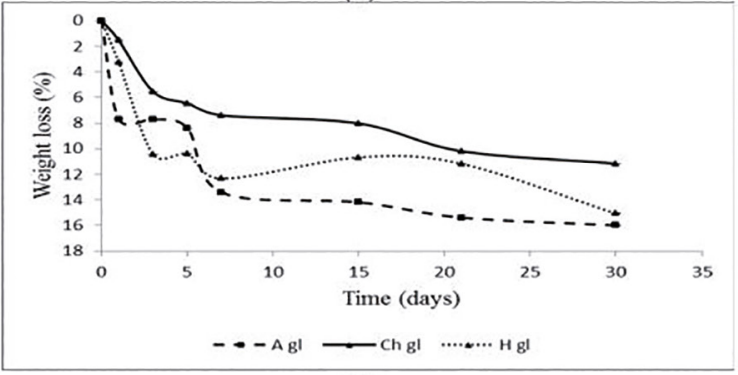

(d)

Figure 5: Results of (a) swelling ratio and (b) weight loss of alginate, chitosan and hybrid scaffolds with glycerol.

with glycerol values were higher than the scaffold without glycerol, indicating that the presence of glycerol had increased the swelling behavior of the scaffolds.

The highest weight loss corresponds to the alginate scaffold with glycerol, accounting for $16 \%$ weight loss compared with $15 \%$ from the hybrid scaffold with glycerol and $11.1 \%$ from the chitosan scaffold with glycerol on the thirtieth day. Compared to the scaffolds without glycerol, the scaffolds containing glycerol presented less weight loss in all scaffolds, suggesting that the presence of glycerol worked as a stabilizer of the scaffold structures ${ }^{36,37}$.

\subsection{Cell viability assay}

Cell viability and proliferation on a material are indications of material compatibility, suggesting potential tissue engineering applications. None of the samples decreased cell viability.

After the 24 and $48 \mathrm{~h}$, all scaffolds with and without glycerol presented absorbance values above the negative control (Figure 6). After $48 \mathrm{~h}$, chitosan scaffolds with and without glycerol presented $0.46 \%$ and $3.11 \%$ higher absorbance compared to the positive control, respectively, indicating the possibility of cell proliferation in these scaffolds. The hybrid scaffold without glycerol presented absorbance values close to the positive control (3.67\% above) after 48 $\mathrm{h}$, also indicating possible cell proliferation.

\subsubsection{Crystal violet}

After the 24-hour period, all scaffolds presented results above the positive control values, and the chitosan scaffold with glycerol presented $45.2 \%$ greater absorbance than the negative control (Figure 7); after the 48-hour period, the greater absorbance rate was the hybrid scaffold without glycerol, presenting a rate 37.6 $\%$ higher than the positive control, indicating possible cell proliferation. In this assay, it could be concluded that the blend of alginate and chitosan improved the action of the polymers, compared to the results for the pure substances, because the hybrid scaffold presented a relevant result after $48 \mathrm{~h}$.

Analyzing the two assays (MTT and violet crystal), the results of the hybrid scaffold showed satisfactory biological results in both experiments, with absorbance values near and above the positive control, respectively. This indicates good compatibility and potential as a biomaterial.

\subsection{In vitro degradation study}

Degradation of chitosan and hybrid scaffolds with and without glycerol was studied by immersing the scaffolds in PBS solution containing lysozyme. The degradation rate was analyzed by SEM (Figure 8).

All scaffolds presented degradation of their structures on the seventh day of the assay (Figure 8), confirmed by the concentration peaks of reduced sugars (Figure 9). The hybrid scaffold without glycerol presented incresead degradation, compared to the hybrid scaffold with glycerol. The concentration of reduced sugars incresead by the seventh day, followed by stabilization on the tenth day. The presence of glycerol indicated stabilization in the degradation rate r $^{35,36}$. 


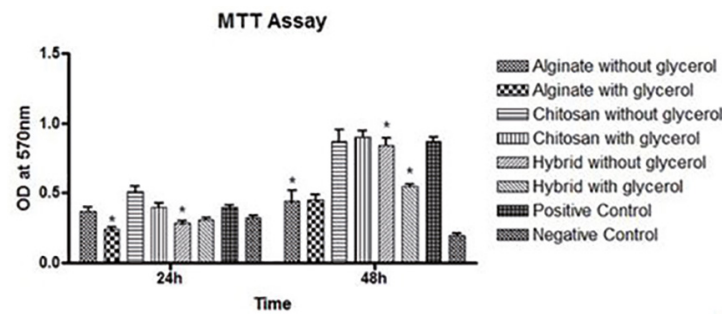

Figure 6: Cellular viability assay using MTT after $24 \mathrm{~h}$ and $48 \mathrm{~h}$ of the alginate, chitosan and hybrid scaffolds without and with glycerol. *Significant statistic difference $(\mathrm{p}<0.05)$ in related to the positive control.

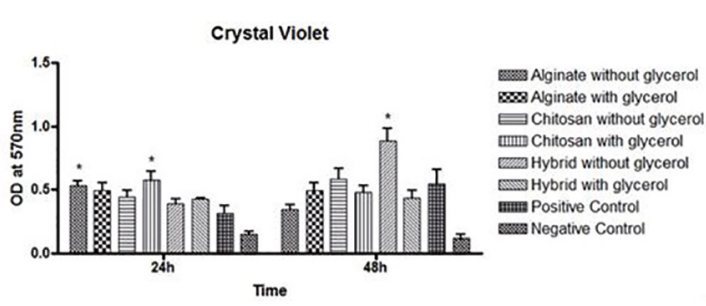

Figure 7: Cellular viability assay using crystal violet after $24 \mathrm{~h}$ and $48 \mathrm{~h}$ of the alginate, chitosan and hybrid scaffolds without and with glycerol. *Significant statistic difference $(\mathrm{p}<0.05)$ in related to the positive control.

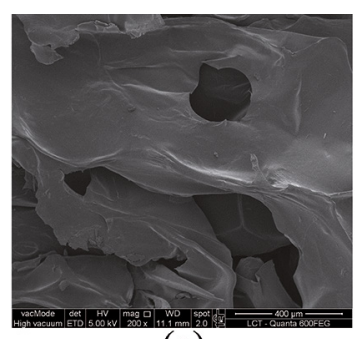

(a)

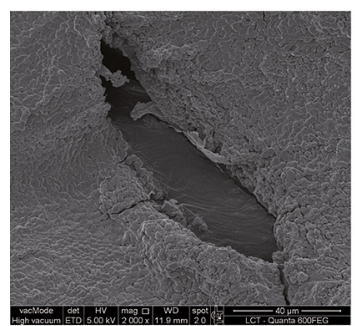

(c)

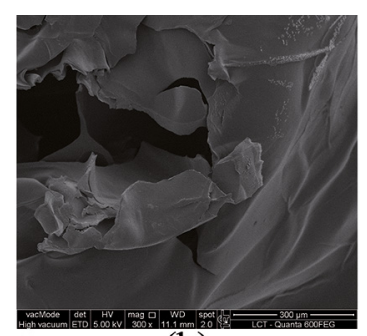

(b)

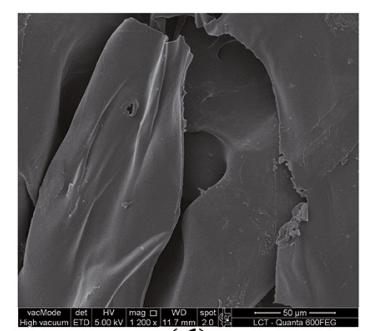

(d)
Figure 8: SEM of (a) chitosan without glycerol, (b) chitosan with glycerol, (c) hybrid without glycerol and (d) hybrid with glycerol scaffolds in the seventh day of assay.

\subsection{In vitro biomineralization study}

Biomineralization of alginate, chitosan and hybrid scaffolds with and without glycerol was studied by immersing the scaffolds in the SBF solution. The mineral deposition in the scaffolds was analyzed by SEM (Figure 10).

Chitosan with and without glycerol presented an incidence of mineral deposition compared to the other

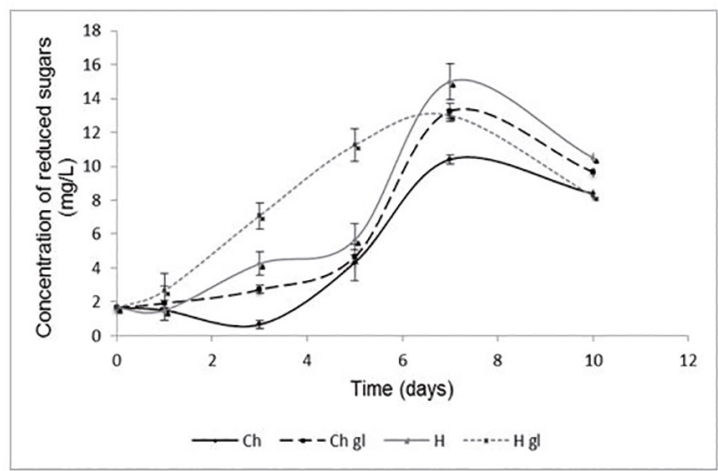

Figure 9: Concentration of reduced sugars of the hybrid and chitosan scaffolds without and with glycerol.

scaffolds after three days of assay (Figure 10c; 10d). The presence of apatite crystals could be confirmed by the EDS (Figure $10 \mathrm{c}^{\mathrm{l}} ; 10 \mathrm{~d}^{\mathrm{l}}$ ), indicated by the presence of $\mathrm{Ca}, \mathrm{P}, \mathrm{Mg}$, K. In the hybrid scaffold without glycerol, apatite crystals also appeared on the third day (Figure 10a; 10b). On the seventh day, the incidence of hydroxyapatite increased in the hybrid scaffold with and without glycerol (Figure 11a; $11 b$ ), and on the fifteenth day the chitosan scaffold with and without glycerol presented evidence of mineralization with the apatite crystals (Figure 11c; 11d).

\section{Conclusions}

Alginate, chitosan and hybrid scaffolds with and without glycerol were developed and characterized. Tensile tests presented results indicating that the use of glycerol and the interaction between alginate and chitosan as a hybrid fiber were associated with a trend of increasing tenacity values. Hybrid fibers presented an increase of $27.3 \%$ and $55.2 \%$ in tenacity values, compared to chitosan and alginate fibers, respectively. DSC/TG indicated an interaction between the polymers in the thermal analysis. The swelling study and weight loss demonstrated that the scaffolds containing glycerol presented less weight loss and even higher water absorption values in all scaffolds, compared to the scaffolds without glycerol, indicating that glycerol is a stabilizer. None of the alginate, chitosan and hybrid scaffolds with and without glycerol decreased cell viability. In the MTT assay, chitosan with and without glycerol presented higher absorbance than the positive control, indicating cell proliferation. On the third day of the biomineralization assay, chitosan with and without glycerol and the hybrid scaffold without glycerol presented apatite crystals. The degradation study showed that glycerol may have worked as a stabilizer.

Considering all the results, it can be concluded that the hybrid scaffold presented satisfactory mechanical and biological results, due to the increase in tenacity, compared to alginate and chitosan, potential cell proliferation after $48 \mathrm{~h}$ in cellular studies and the incidence of apatite crystals since the third day of assay in the biomineralization study. 


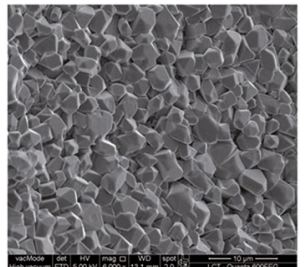

(a)

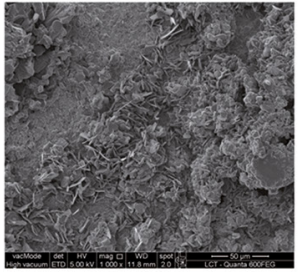

(b)

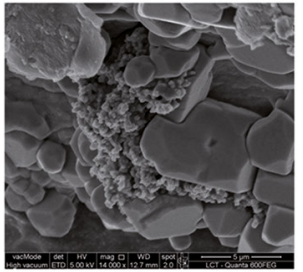

(c)

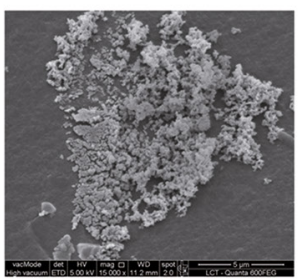

(d)

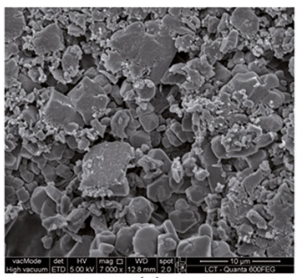

(e)

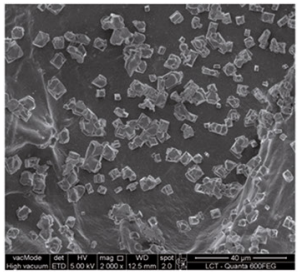

(f)

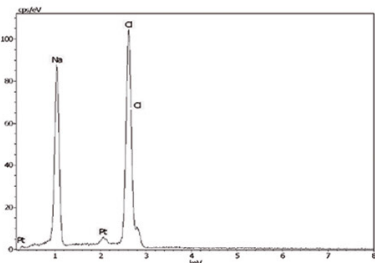

$\left(\mathrm{a}^{\mathrm{l}}\right)$

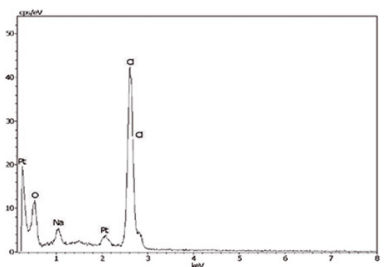

$\left(b^{1}\right)$

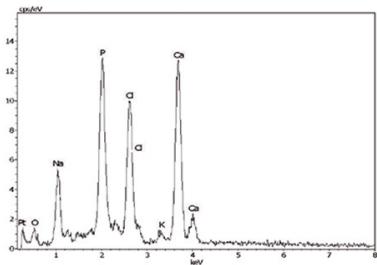

(cl)

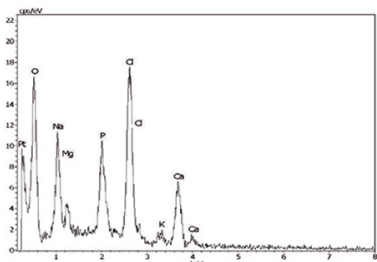

$\left(d^{\prime}\right)$

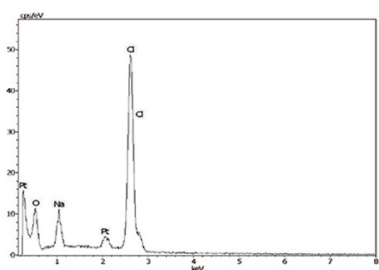

$\left(\mathrm{e}^{\mathrm{l}}\right)$

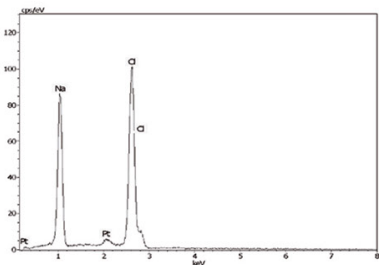

(f1)
Figure 10: SEM and EDS of $\left(a ; a^{l}\right)$ alginate without glycerol, $\left(b ; b^{l}\right)$ alginate with glycerol, $\left(\mathrm{c} ; \mathrm{c}^{\mathrm{l}}\right)$ chitosan without glycerol, $\left(\mathrm{d} ; \mathrm{d}^{\mathrm{l}}\right)$ chitosan with glycerol, $\left(\mathrm{e} ; \mathrm{e}^{\mathrm{l}}\right)$ hybrid without glycerol and $\left(\mathrm{f} ; \mathrm{f}^{\mathrm{f}}\right)$ hybrid with glycerol scaffolds in third day of assay.

This attests to the fact that the combination of the two polymers can be considered an advance in the development of biomaterial. All tests showed promising results, but other

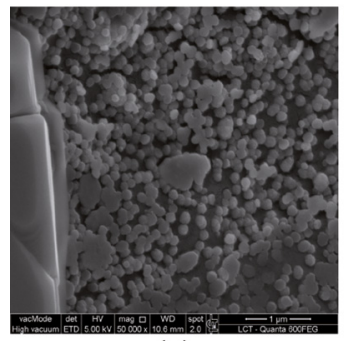

(a)

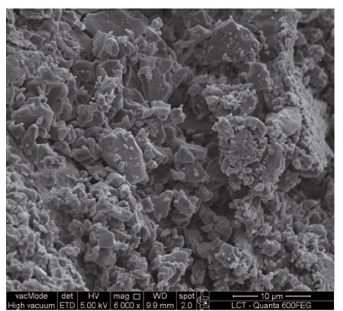

(c)

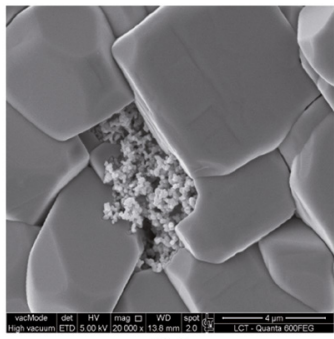

(b)

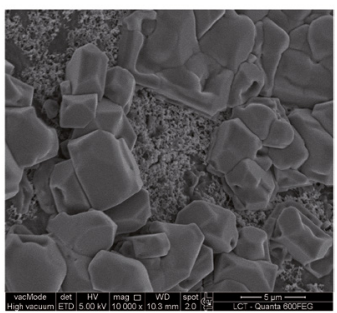

(d)
Figure 11. SEM of (a) chitosan without glycerol and (b) chitosan with glycerol scaffolds in the seventh day of assay; (c) hybrid without glycerol and (d) hybrid with glycerol scaffolds in the tenth day of assay.

essays are needed for a better evaluation for its application in bone tissue engineering.

\section{Acknowledgements}

The authors gratefully acknowledge University of São Paulo, CAPES, FAPESP (2013/08617-7), CNPq Brazil for the financial support. The authors are grateful to Centro Integrado de Pesquisa (CIP) - Bauru School of Dentistry USP for providing some work facilities.

\section{References}

1. Chen Q, Liang S, Thouas GA. Elastomeric biomaterials for tissue engineering. Progress in Polymer Science. 2013;38(3-4):584-671.

2. Vacanti JP, Vacanti CA. The History and Scope of Tissue Engineering. In: Lanza R, Langer R, Vacanti J, eds. Principles of Tissue Engineering. London: Elsevier; 2013. p. 3-8.

3. Ayaz HGS, Perets A, Ayaz H, Gilroy KD, Govindaraj M, Brookstein $\mathrm{D}$, et al. Textile-templated electrospun anisotropic scaffolds for regenerative cardiac tissue engineering. Biomaterials. 2014;35(30):8540-8552.

4. Doser M, Planck H. Textiles for implants and regenerative medicine. In: Bartels VT, ed. Handbook of Medical Textiles. Cambridge: Woodhead Publishing; 2011. p. 132-152.

5. Tamayol A, Akbari M, Annabi N, Paul A, Kadhemhosseini A, Juncker D. Fiber-based tissue engineering: Progress, challenges and opportunities. Biotechnology Advances. 2013;31(5):669-687.

6. Braghirolli DI, Steffens D, Pranke P. Electrospinning for regenerative medicine: a review of the main topics. Drug Discovery Today. 2014;19(6):743-753. 
7. Venkatesan J, Bhatnagar I, Manivasagan P, Kang KH, Kim SK. Alginate composites for bone tissue engineering: A review. International Journal of Biological Macromolecules. 2015;72:269-281.

8. Bose S, Roy M, Bandyopadhyay A. Recent advances in bone tissue engineering scaffolds. Trends in Biotechnology. 2012;30(10):546-554.

9. Wang P, Tawiah B, Tian A, Wang C, Zhang L, Fu S. Properties of alginate fiber spun-dyed with fluorescent pigment dispersion. Carbohydrate Polymers. 2015;118:143-149.

10. Venkatesan J, Bhatnagar I, Kim SK. Chitosan-alginate biocomposite containing fucoidan for bone tissue engineering. Marine Drugs. 2014;12(1):300-316.

11. Croisier F, Jérôme C. Chitosan-based biomaterials for tissue engineering. European Polymer Journal. 2013;49(4):780-792.

12. Li Z, Ramay HR, Hauch KD, Xiao D, Zhang M. Chitosan-alginate hybrid scaffolds for bone tissue engineering. Biomaterials. 2005;26(18):3919-3928.

13. Simsek-Ege FA, Bond GM, Stringer J. Polyelectrolyte complex formation between alginate and chitosan as a function of $\mathrm{pH}$. Journal of Applied Polymer Science. 2003;88(2):346-351.

14. Baysal K, Aroguz AZ, Adiguzel Z, Baysal BM. Chitosan/ alginate crosslinked hydrogel: Preparation, characterization and application for cell growth purposes. International Journal of Biological Macromolecules. 2013;59:342-348.

15. Lee K, Ahn S, Choi CH, Lee D, Jung WK, Kim G. Functionallized alginate/chitosan biocomposites consisted of cylindrical struts and biologically designed for chitosan release. Current Applied Physics. 2014;14(8):1105-1106.

16. Iwasaki N, Yamane ST, Majima T, Kasahara Y, Minami A, Harada K, et al. Feasibility of polysaccharide hybrid materials for Scaffolds in cartilage tissue engineering: evaluation of chondrocyte adhesion to polyion complex fibers prepared from alginate and chitosan. Biomacromolecules. 2004;5(3):828-833.

17. Hu WW, Yu HN. Coelectrospinning of chitosan/alginate fibers by dual-jet system for modulating material surfaces. Carbohydrate Polymers. 2013;95(2):716-727.

18. Hyland LL, Taraban MB, Hammouda B, Yu YB. Mutually reinforced multicomponent polysaccharide networks. Biopolymers. 2011;95(12):840-851.

19. Maluf E, Kolbe W. Textile fibers. In: Technical Textile Industry Data. $2^{\text {nd }}$ ed. São Paulo: Institute for Technological Research and Brazilian Textile and Confection Industry Association (ABIT); 2003. p. 1-64.

20. International Organization for Standardization (ISO). ISO 5084:1996. Determination of thickness of textiles and textile products. Geneva: International Organization for Standardization; 1996.

21. International Organization for Standardization (ISO). ISO 2060:1994. Textiles -- Yarn from packages -- Determination of linear density (mass per unit length) by the skein method. Geneva: International Organization for Standardization; 1994.
22. International Organization for Standardization (ISO). ISO 1139:1973. Textiles - Designation of yarns. Geneva: International Organization for Standardization; 1973.

23. International Organization for Standardization (ISO). ISO 139:2005. Textiles - Standard atmospheres for conditioning and testing. Geneva: International Organization for Standardization; 2005.

24. ASTM International. ASTM D3822. Standard Test Method for Tensile Properties of Singles Textile Fibers. West Conshohocken: ASTM International; 2007.

25. Volpato LE, Oliveira RC, Epinosa MM, Bagnato VS, Machado MAAM. Viability of fibroblasts cultured under nutritional stress irradiated with red laser, infrared laser, and red light-emitting diode. Journal of Biomedical Optics. 2011;16(7):075004.

26. Ghose TK. Measurement of cellulase activities. Pure and Applied Chemistry. 1987;59(2):257-268.

27. Kokubo T, Takadama H. How useful is SBF predicting in vivo bone bioactivity? Biomaterials. 2006;27(15):2907-2915.

28. Hearle JWS, Morton WE. Physical Properties of Textile Fibres. $4^{\text {th }}$ ed. Cambridge: Woodhead Publishing; 2008.

29. Niekraszewicz B, Niekraszewicz A. The structure of alginate, chitin and chitosan fibres. In: Eichhorn SJ, Hearle JWS, Jaffe M, Kikutani T, eds. Handbook of Textile Fibre Structure Volume 2: Natural, Regenerated, Inorganic and Specialist Fibres. Cambridge: Woodhead Publishing; 2009. p. 266-306.

30. Anandjwala RD. Role of advanced textile materials in healthcare. In: Anand S, Kennedy JF, Miraftab M, Rajendran S, eds. Medical Textiles and Biomaterials for Healthcare. Cambridge: Woodhead Publishing; 2006. p. 90-98.

31. Kaswell ER. Wellington Sears Handbook of Industrial Textiles. New York: Wellington Sears Company; 1963.

32. Wendlandt WW. Thermal Analysis. New York: John Wiley \& Sons; 1986.

33. Price DM, Hourston DJ, Dumont F. Thermogravimetry of Polymers. In: Meyers RA, ed. Encyclopedia of Analytical Chemistry. Chichester: John Wiley \& Sons; 2000. p. 8094-8105.

34. Lima PA, Resende CX, Soares GD, Anselme K, Almeida LE. Preparation, characterization and biological test of 3D-scaffolds based on chitosan, fibroin and hydroxyapatite for bone tissue engineering. Materials Science and Engineering: $C$. 2013;33(6):3389-3395.

35. Valente JFA, Valente TAM, Alves P, Ferreira P, Silva A, Correia, IJ. Alginate based scaffolds for bone tissue engineering. Materials Science and Engineering: C. 2012;32(8):2596-2603.

36. Bradbury SL, Jakoby WB. Glycerol as an enzyme-stabilizing agent: effects on aldehyde dehydrogenase. Proceedings of the National Academy of Sciences of the United States of America. 1972;69(9):2373-2376.

37. Vagenende V, Yap MGS, Trout BL. Mechanisms of protein stabilization and prevention of protein aggregation by glycerol. Biochemistry. 2009;48(46):11084-11096. 